Vol. XX, No. 3

\title{
The Dry Hillsides
}

\section{by K. F. Best, Swift Current}

In our series, we have come from the arid dune sand vegetation, through the sandhills and the eroded slopes. As conditions improve we find a greater number of species present. In this issue let us look at two native perennials, one from the Sandalwood family and the other, a mustard.

The Plale Comandra (Comandra pallida) belongs to the Sandallwood family. The Pale Comandra máy be partly parasitic on the roots of other plants. The creeping white rootstalks send up several plants in erect bunches, 3 to 18 inches in height. The leaves are without stalks, alernate on the stem and are pale green with a whitish bloom.

The flower clusters are at the ends of the stems. The centre flowers open first. The color varies from greenishwhite to a pinkish shade. It is the five-lobed calyx that gives the appearance of greenish-white petals on the tiny flowers. The leaves as well as the flower buds are often a delicate shade of pink. The fruit is a small drupe-a fleshy fruit with a hard, nut-like seed in the centre. The plants are frequently attacked by a tiny insect which causes small round

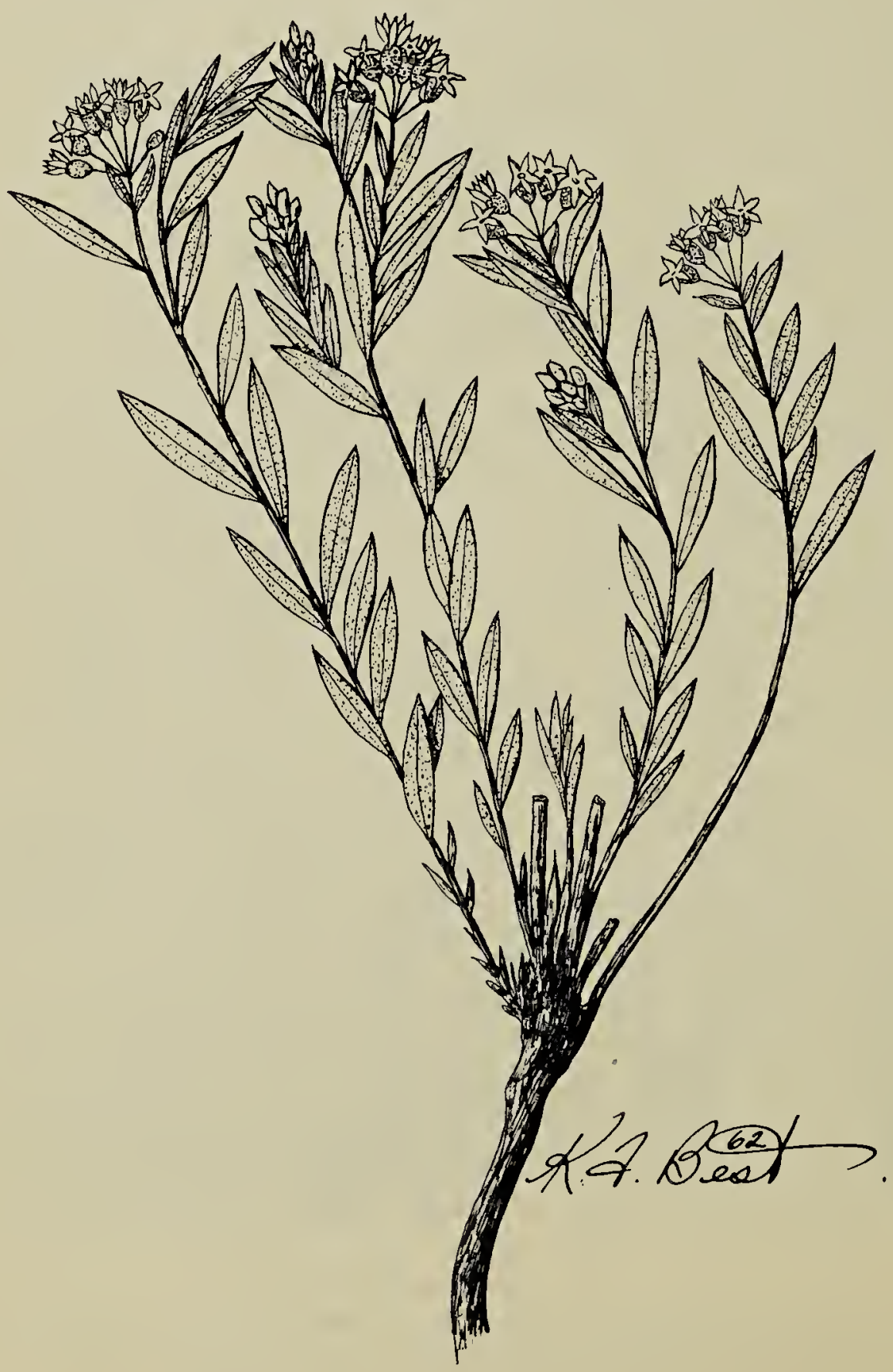




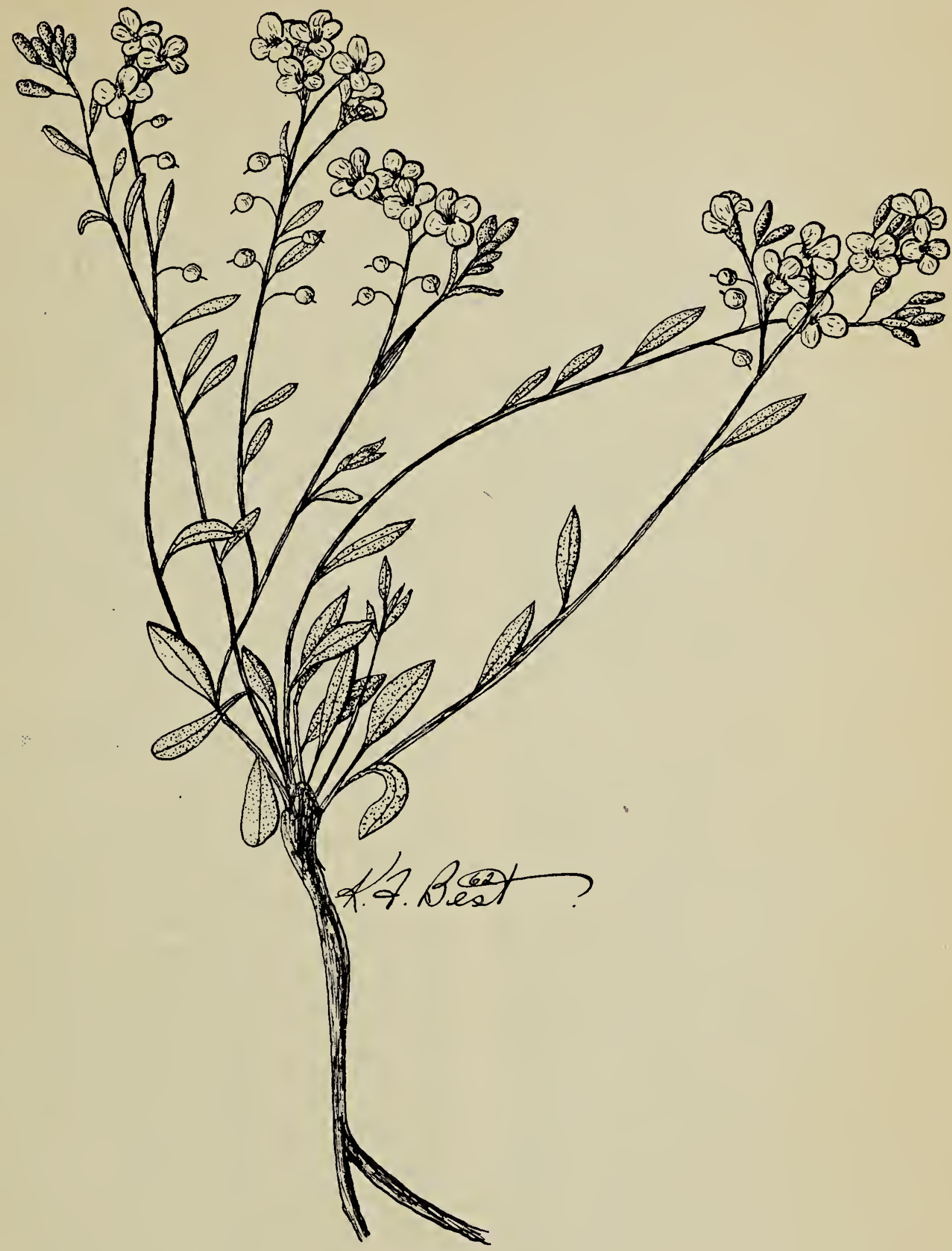

galls that are often mistaken for the fruit.

Budding usually occurs in mid-May but the plants are quite slow to bloom.

One of our native mustards, the Sand Bladder-pod (Lesquerella arenos $a$ ) is a slender-stemmed perennial which grows close to the ground. The leaves are mostly basal and a gray-green so frequent among prairie plants that are protected with fine hairs. The pale pink buds open into dull yellow or reddish tinged four-petalled flowers about $1 / 4$ inch across. As the name suggests, the pods resemble small bladders and are borne on curved stalks.

Flowering generally occurs during the early part of May. 